\title{
AS TRAJETÓRIAS DA COBERTURA E DO USO DO SOLO NAS UNIDADES DA FEDERAÇÃO DO BRASIL: UMA ANÁLISE DE CLUSTERING DE SÉRIES TEMPORAIS 1985-2018
}

\section{Caio César Soares Gonçalves}

Fundação João Pinheiro (FJP) e Escola Nacional de Ciências Estatísticas do Instituto Brasileiro de Geografia e Estatística (ENCE/IBGE)

Rio de Janeiro - RJ - Brasil

E-mail: ccsgonc@gmail.com

ORCID: https://orcid.org/0000-0002-3366-7560

\section{Bruno Freitas Cortez}

Escola Nacional de Ciências Estatísticas do Instituto Brasileiro de Geografia e Estatística (ENCE/IBGE)

Rio de Janeiro - RJ - Brasil

E-mail: bruno2977@gmail.com

ORCID: https://orcid.org/0000-0002-8667-6137

Recebido em 07/01/2021 aprovado em 22/04/2021.

DOI: http://dx.doi.org/10.5380/guaju.v7i1.78791

\section{Resumo}

O presente trabalho tem como objetivo identificar as diferenciações espaçotemporais da cobertura e uso do solo no território brasileiro sob o recorte político-administrativo das Unidades da Federação entre os anos de 1985-2018. A metodologia utilizada envolveu duas abordagens para considerar o tempo e o espaço na análise. A primeira com a comparação das transições do uso e cobertura do solo entre um ponto inicial (1985) e um ponto final (2018), permitindo evidenciar o montante final das alterações do solo brasileiro utilizando a análise de clustering. A segunda considerou a dinâmica entre os anos de 1985 a 2018, permitindo verificar como ocorreram as trajetórias das mudanças utilizando análise de clustering de séries temporais. Os principais resultados encontrados apontaram que a transformação de floresta natural para pastagem representou a principal transição do solo brasileiro; os estados litorâneos da Bahia até o Rio Grande do Sul, e também Minas Gerais, apresentaram uma dinamicidade em termos dos tipos das transições ocorridas principalmente envolvendo atividades agropastoris; as trajetórias da transição de floresta natural para pastagem podem ser entendidas como um "cinturão" sudoeste-nordeste em relação ao centro do 
Brasil, sendo que reduz as magnitudes à medida que se caminha para direita e esquerda do "cinturão"; e todas as UFs apresentaram aumentos na transformação de floresta natural para pastagem nos últimos anos.

Palavras-chave: Cobertura do solo. Uso do solo. Análise multivariada. Clustering de Séries Temporais. Unidades da Federação.

\title{
The trajectories of coverage and land use in Federative Units of Brazil: a time series clustering analysis of 1985-2018
}

\begin{abstract}
This paper aims to identify the Spatial-temporal differentiations of land cover and land use in Brazilian territory under the political-administrative clipping of the Units of the Federation between the years 1985-2018. The methodology used involved two approaches to consider time and space in the analysis. The first one with the comparison of land use and land cover transitions between a starting point (1985) and an end point (2018), allowing to highlight the final amount of changes in Brazilian land using clustering analysis. The second considered the dynamics between the years 1985 to 2018, allowing us to verify how the trajectories of the change occurred using time series clustering analysis. The main results found pointed out that the transformation from natural forest to pasture represented the major soil transition in Brazil; the coastal states from Bahia to Rio Grande do Sul and also Minas Gerais, showed a dynamism in terms of the types of transitions that occurred mainly involving agricultural activities; the trajectories of the transition from natural forest to pasture can be understood as a southwest-northeast "belt" relative to central Brazil, with decreasing magnitudes as one moves to the right and left of the "belt"; and all states showed increases in the transformation from natural forest to pasture in recent years.
\end{abstract}

Keywords: Land cover. Land use. Multivariate analysis. Time Series Clustering. Federative Units 


\section{Introdução}

A literatura sobre a relação entre população, meio ambiente e desenvolvimento das décadas de 1970 e 1980 centravam em uma discussão sobre o crescimento demográfico com posições semelhantes a defendida por neomalthusianistas (NOBRE, 2002; EHRLICH, 1968; HARDIN, 1968). As contradições entre meio ambiente e desenvolvimento apresentadas nesse período foram sintetizadas no relatório do Clube de Roma (MEADOWS et al., 1972) e também na Conferência de Estocolmo de 1972. No entanto a discussão de que não poderia existir desenvolvimento e preservação do meio ambiente ao mesmo tempo abriu espaço e reformulou-se a partir do surgimento do conceito de desenvolvimento sustentável no final da década de 1980.

A definição apresentada pelo relatório Brundtland (COMISSÃO MUNDIAL SOBRE MEIO AMBIENTE E DESENVOLVIMENTO, 1991) e debatida na Conferência das Nações Unidas sobre Meio Ambiente e Desenvolvimento, também conhecida por Eco-92 ou Rio-92, diz que desenvolvimento sustentável é aquele desenvolvimento que satisfaz as necessidades das gerações presentes, porém sem prejudicar a capacidade das gerações futuras de satisfazer suas próprias necessidades.

O conceito acumulou críticas ao longo dos anos apontando incompatibilidades que persistiram mesmo com a transformação das agendas pós-Rio-92. Conforme Veiga (2017), o crescimento econômico continua sendo uma das dimensões essenciais por trás do ideal de desenvolvimento, sendo explicitamente citado no oitavo Objetivo de Desenvolvimento Sustentável (ODS-8) da atual Agenda 2030 que objetiva promover o crescimento econômico sustentado.

Mesmo com uma definição que pressupõe um desenvolvimento equilibrado com equidade ao não poluir o meio ambiente e nem destruir a base de recursos naturais, as incompatibilidades entre desenvolvimento e sustentabilidade ambiental se agravaram em um contexto de crescimento populacional que pressiona por mais elevados patamares de produção e consumo (SAWYER, 2002), além das ações antrópicas de ocupação desordenada e exploração da grande extensão territorial do Brasil que acumula historicamente interferências no ambiente.

No Brasil, a existência de pluralidade dos biomas que possuem diversidades intra e inter ecossistemas é amplamente reconhecida. No entanto sofreram principalmente processo de desmatamento ao mesmo tempo que foram submetidas à intensificação cada 
vez maior e diversa dos modos de exploração dos recursos naturais conforme os estudos específicos dos biomas brasileiros como um todo ou parte de regiões selecionadas com escalas diversas, por exemplo: Amazônia em Vieira, Santos Junior e Toledo (2014) e Batistella e Moran (2007); Cerrado em Sawyer (2002) e Souza e Galvão (2019), Mata Atlântica em Neves et al (2019); e Caatinga em Fernandes et al (2015).

Um dos confrontos existentes pode ser sintetizado como a oposição das forças que pregam os interesses da produção agropecuária e silvicultura em grande escala e aquelas que valorizam o uso menos impactante dos recursos naturais e do trabalho (VIEIRA; SANTOS JUNIOR; TOLEDO, 2014). Adiciona-se ainda as transformações oriundas da urbanização em que a concentração e a densidade urbana são apontadas como uma das principais causas da desorganização do ambiente, produção de resíduos e um consumo exacerbado de recursos (MINISTÉRIO DO MEIO AMBIENTE, 2015).

Dessa forma, as atividades humanas vêm alterando a dinâmica de ocupação e do uso do solo. E conforme demonstrado por Becker (2001) ao utilizar um modelo macrorregional para a Amazônia, identifica-se sub-regiões com velocidades díspares de transformações. Esse mesmo olhar pode ser aplicado sobre o conjunto dos biomas para obter uma visão geral da dinâmica do uso e da cobertura do solo do país ao longo dos anos.

Além disso, o setor público brasileiro apresenta contradições ao implementar medidas ambientais regulamentadoras conflitantes entre seus diferentes órgãos que atuam no mesmo espaço. Isso resulta na criação de sinalizações antagônicas e, nas palavras de Vieira, Santos Junior e Toledo (2014, p. 392), "temporalmente desconexas em relação ao meio ambiente e à gestão territorial". Vale lembrar que é de competência comum da União, dos estados, do Distrito Federal e dos municípios a proteção dos documentos, das obras e de outros bens de valor histórico, artístico e cultural, dos monumentos, das paisagens naturais notáveis e dos sítios arqueológicos; a proteção do meio ambiente e do combate à poluição em qualquer de suas formas e a preservação das florestas, da fauna e da flora, conforme Art. 23 da Constituição Federal de 1988. O artigo seguinte afirma sobre a competência de legislar concorrentemente à União, aos estados e ao Distrito Federal sobre a matéria de florestas, caça, pesca, fauna, conservação da natureza, defesa do solo e dos recursos naturais, proteção do meio ambiente e controle da poluição (Art. 24 da CF/1988). Em termos dos direitos, "todos têm direito ao meio ambiente ecologicamente equilibrado, bem de uso comum do povo e essencial à sadia qualidade de vida" - Art. 225 da CF/1988 (BRASIL, 1988). 
Dessa forma, sob o arcabouço de que em termos da administração pública, os estados e o Distrito Federal, por exemplo, podem implementar políticas, planos, programas, projetos e ações que assegurem à população o acesso a diversos serviços e a seus direitos. Um exemplo é o ICMS Ecológico implantado por Minas Gerais que se traduz em transferências do estado para os municípios conforme critérios ambientais. Nesse sentido, análises com recortes políticos-administrativos podem ser utilizadas como forma de evidenciar responsabilização do setor público no sentido de quais respostas o estado deveria fornecer diante das pressões causadoras dos problemas ambientais. Por isso é relevante conhecer o estado da situação do meio ambiente utilizando indicadores ambientais sob uma escala mais agregada.

D’Antona, Cak e VanWey (2007) afirmam que em escalas em níveis mais agregados, como municípios, estado ou região, perde-se o entendimento de processos e motivações particulares em detrimento de uma percepção de tendências macro. No entanto as escalas em níveis mais desagregados, como propriedade rural ou um conjunto de propriedades, possibilitam a maior compreensão das motivações que geraram as mudanças, porém existirá uma dificuldade em extrapolar particularidades de cada estudo para regiões mais extensas.

Diante disso, este artigo visa identificar as diferenciações espaço-temporais da cobertura e uso do solo no território brasileiro sob o recorte político-administrativo das Unidades da Federação entre os anos de 1985-2018.

A metodologia para evidenciar as diferenças no tempo e no espaço contemplando um conjunto amplo de dados será a análise de clustering em dois pontos específicos do tempo (1985 e 2018), sendo que os destaques encontrados serão analisados pela dinâmica da série temporal anual por meio da técnica de clustering de séries temporais. Além de identificar as transições do uso e cobertura do solo mais relevantes, o resultado identificará as semelhanças e diferenças dessas transições entre as UF's, construindo uma percepção de tendências gerais do estado do uso e cobertura do solo ao longo do tempo.

A possibilidade de uma série longa e consistente metodologicamente para o conjunto de Unidades da Federação, dos biomas e do país dá-se pela existência da base construída pelo MapBiomas, iniciativa formada em 2015 por universidades, ONGs e empresas para produção de séries temporais anuais de mapas de cobertura e uso do solo do Brasil (MAPBIOMAS, 2019a). Além dessa vantagem metodológica, outro ponto positivo para essa base é que apresenta além dos estados anuais (floresta natural, floresta plantada, agricultura, pastagem, área não vegetada e corpo d'água, por exemplo) para um recorte geográfico 
específico, produz informações das transições desses estados. Por exemplo, nessa base de dados, é possível identificar quantos hectares de floresta natural se converteu para o uso da agricultura, ou, ainda, quantos hectares se tornaram áreas não vegetadas (infraestrutura urbana e mineração).

Não foi identificado na literatura um estudo como o proposto por esse trabalho. O que o torna inédito ao aplicar técnicas estatísticas da análise multivariada e de séries temporais para analisar o uso e cobertura do solo, contribuindo para a literatura ao incorporar uma forma de análise.

Além dessa introdução, este artigo está dividido da seguinte forma: apresentação dos fundamentos sobre o uso e a cobertura do solo; metodologia e base de dados empregada no presente estudo; as análises dos resultados encontrados; finaliza com considerações finais.

\section{Fundamentos}

Briassoulis (2019) argumenta que estudos sobre mudanças do uso do solo nem sempre usam as mesmas definições de termos centrais sobre o tema, como "uso do solo" e "cobertura do solo". Essas definições podem variar de acordo com o objetivo de aplicação e o contexto de utilização. Dessa forma, embora a autora aponte que seja importante estar atento às possíveis definições mais frequentemente usadas desses termos, ela destaca que uso do solo e cobertura do solo não são sinônimos e é preciso distinguir essas diferenças para sua correta utilização.

De forma genérica, o termo cobertura de solo remete a ideia do estado físico da superfície do solo, sejam agrícolas, florestas ou montanhas, por exemplo. Já o uso do solo relaciona-se com a maneira e a finalidade de uso do solo. Logo, uma área com cobertura de solo florestal, por exemplo, pode ter um uso de produção de madeira, ser de uso recreativo, ter uso misto (tanto produção de madeira como de recreação), ser uma floresta natural, entre outros. Sendo assim, o uso do solo muitas vezes provocará mudanças na cobertura do solo, no entanto essa cobertura poderá se alterar mesmo que seu uso permaneça o mesmo. Vale destacar que essa distinção conceitual, embora seja relativamente fácil na teoria, não é tão simples na prática uma vez que os dados disponíveis nem sempre deixam clara essa diferenciação entre uso e cobertura (BRIASSOULIS, 2019). 
Côrtes e Dantona (2014) apontam que, embora os primeiros estudos sobre uso e cobertura do solo tenham surgido no século XIX, é a partir da década de 1980 que ocorre o avanço nesse campo de estudos decorrente da preocupação quanto à intensificação do desmatamento das florestas tropicais. Inicialmente as investigações sobre o tema foram conduzidas por diversas disciplinas, mas de modo não integrado. Pebley (1998) acrescenta que esses estudos iniciais algumas vezes eram dificultados pela falta de dados adequados. Como consequência, muitos deles eram limitados a análises descritivas de dados censitários ou pequenos estudos de caso cujas conclusões são de difícil comparação devido a diferenças nos métodos, nas variáveis ou nas áreas de estudo.

Essa característica começa a ser revertida em 1994 com o projeto Land-use and Landcover Change (LUCC) que tinha como objetivo avaliar a ação das forças humanas no uso e cobertura do solo e seus resultantes impactos ambientais e socais. Destaca-se ainda, no fim dessa década, uma perspectiva explicativa originada de um modelo multidimensional e complexo que compreende essas mudanças como consequência de um arranjo de variados fatores, locais e escalas espaciais. Desde então, novidades temáticas e metodológicas vêm sendo incorporadas nos estudos, como, por exemplo, a inclusão de dados demográficos, tecnologia do sensoriamento remoto, entre outros. Assim, esse campo de estudo entra no século XXI fortalecido em sua característica multidisciplinar e aberto às análises multiescalares para dar conta da cada vez maior complexidade do seu objeto (CÔRTES; DANTONA, 2014).

Aguiar (2003) acrescenta que a escala de preocupação na relação entre a mudança nos padrões de uso e cobertura do solo e os seus possíveis impactos ambientais e socioeconômicos vão desde o nível global ao local. Em termos globais, é possível pensar em questões como aquecimento global, desertificação, perda da biodiversidade, destruição de habitats, disponibilidade de alimentos, processos de migração humana, dentre outros. Em termos regionais, destacam-se questões como poluição do ar e da água, degradação do solo e eutrofização de corpos d'água, por exemplo. Já em nível local, a autora cita problemas de erosão, sedimentação, contaminação e extinção de espécies, produtividade da terra, entre outros. Nas áreas urbanas, existem preocupações como, por exemplo, a expansão dos subúrbios e áreas industriais, causando perda de áreas para agricultura e de vegetação natural.

Especificamente para o caso brasileiro, Batistella e Moran (2007) destacam que o processo mais importante de fragmentação da paisagem em nível regional, por sua abrangência geográfica e relevância socioambiental, é o desmatamento de florestas 
tropicais, em particular da Amazônia, que pode trazer consequências até para o nível global. Não obstante, outras regiões e biomas brasileiros estão sofrendo, de forma similar, alterações devido a ação humana. As vegetações naturais do Cerrado (SOUZA; GALVÃO, 2019) e a Caatinga (FERNANDES et al, 2015), por exemplo, vem tendo suas áreas convertidas principalmente para a prática de pastagem. O solo urbano, por sua vez, também vem tomando lugar de áreas que antes eram cobertas por vegetações densas ou rasteiras (NEVES et al., 2019). Dessa forma, o Brasil, com grande dimensão territorial e diversidade de ecossistemas, convive simultaneamente com inúmeras transições no uso e cobertura de seu solo.

\section{Metodologia}

Quanto maior o número de variáveis, mais complexa torna-se a análise por métodos de estatística univariada. A área da estatística multivariada surgiu para lidar nessas situações de redução de dimensionalidade. É nesse contexto que o presente estudo se encaixa, situação em que há um grande número de variáveis para as 27 Unidades da Federação para identificar as diferenciações no espaço e no tempo. A análise de clustering, também conhecida como análise de conglomerados ou classificação, permite identificar grupos que não são conhecidos a priori, que possuam coesão interna e que sejam heterogêneos entre si (MINGOTI, 2005).

A metodologia a ser empregada para a análise dos dados pode ser dividida em duas partes. A primeira identifica os grupos tendo como variáveis de similaridade as transições do uso e cobertura do solo referentes aos pontos iniciais e finais do tempo (1985 e 2018) com a análise de clustering do tipo hierárquico. Basicamente, as técnicas para a construção dos conglomerados podem ser divididas entre hierárquicas e não hierárquicas. A escolha do primeiro método se deu por possuir um caráter mais exploratório que identifica possíveis grupamentos sem a necessidade de um número final de grupos já pré-definido pelo pesquisador (MINGOTI, 2005).

As variáveis de similaridade não foram normalizadas, prática comum nesse tipo de análise, pois, nesse caso específico, as diferenças de magnitudes nas transições são de extrema relevância para o objeto de estudo, o que será melhor explorado na próxima seção. No entanto seus valores foram relativizados pelo tamanho das UFs, uma vez que o mesmo número absoluto de determinada área que transitou de um estado para outro pode ter impacto quase desprezível com relação à área total de uma UF, mas pode ser relevante para uma outra. Afinal as UFs possuem tamanhos muito heterogêneos, variando desde o 
Amazonas com mais de 155 milhões de hectares até o Distrito Federal com apenas 578 mil hectares, aproximadamente.

A partir dos resultados da primeira parte, inicia-se a segunda com uma investigação mais detalhada acerca da dinâmica ao longo dos anos (1985 a 2018), identificando grupos que apresentaram trajetórias similares para os principais destaques em termos de uso e cobertura do solo. A técnica a ser empregada é o clustering de séries temporais que agrupará séries com maior grau de similaridade (levando em consideração diferentes níveis e inclinações). Essa técnica tem ampla aplicação com dados reais, conforme sintetizado por Liao (2005) e Aghabozorgi, Shirkhorshidi e Wah (2015), em áreas como: astronomia, biologia, medicina, meio ambiente, clima, energia, finanças, robótica, música e reconhecimento de voz.

A medida de similaridade escolhida é o Dynamic Time Warping (DTW), desenvolvido por Sakoe e Chiba (1971) e Sakoe e Chiba (1978), que possibilita as séries apresentarem pequenos deslocamentos em intervalos curtos de tempo, diferente da distância euclidiana que calcula a distância ponto a ponto, o que em séries temporais representaria o cálculo no mesmo tempo $t$. Dessa forma, DTW utiliza a ideia de alinhamentos não lineares entre as séries, permitindo o cálculo entre diferentes lags. Além disso, conforme Aghabozorgi, Shirkhorshidi e Wah (2015), DTW possui melhor acurácia que a distância euclidiana.

Basicamente, o DTW é um algoritmo de alinhamento que calcula as distâncias entre todos os pontos de uma série temporal com uma outra, de forma que todos os pontos estejam pelo menos interligado a um ponto da outra série. A decisão sobre esse ponto se dá pela minimização calculada por meio do uso da matriz de distância. O alinhamento se dá ao conjunto final de valores mínimos. Computacionalmente, é útil a definição de janelas de alinhamento para otimizar os cálculos, portanto, efetivamente, não se calcula todas as distâncias, mas um intervalo de distâncias em relação a um ponto da série (GIORGINO, 2009).

Além disso, é possível analisar um conjunto de séries temporais tanto univariado quanto multivariado, sendo que esse último é feito, por exemplo, mediante a interpolação do tempo. 


\section{Base de dados}

O Projeto MapBiomas é uma iniciativa multi-institucional para gerar mapas anuais de cobertura e uso do solo a partir de processos de classificação automática aplicada a imagens de satélite. Os dados gerados são públicos, abertos e gratuitos e abarcam todos os biomas brasileiros (Amazônia, Cerrado, Pantanal, Caatinga, Mata Atlântica e Pampa) e tratam temas transversais como pastagem, agricultura, zona costeira e área urbana.

Em sua coleção 4.1, o MapBiomas revisou todos os mapas anuais de cobertura e uso do solo do Brasil em escala de 30m dos 34 anos disponíveis (1985 a 2018), além de implementar melhorias na acurácia, especialmente nos biomas Cerrado e Amazônia. A base possui compatibilização dos limites de biomas, da divisão entre as Unidades da Federação (pós-Constituição de 1988) e também dos municípios, permitindo análises mais detalhadas em diferentes recortes geográficos. Os aspectos técnicos da metodologia, como os mosaicos utilizados, classificação, filtragem de tempo e espaço, integração, cálculos de transições, cálculo das estatísticas de área e a análise de acurácia, podem ser visualizados em MapBiomas (2019a).

A base de dados do Projeto MapBiomas possui três níveis hierárquicos de classe de detalhamento, conforme apresentado pelo quadro 1.

Quadro 1: Níveis de classe do uso e cobertura do solo

\begin{tabular}{|c|c|c|}
\hline \multirow{4}{*}{1 Floresta } & Nível 2 & $\begin{array}{l}\text { Nível } 3 \\
1.1 .1 \text { Formacão Florestal }\end{array}$ \\
\hline & \multirow{2}{*}{ 1.1 Floresta Natural } & 1.1.2 Formação Savânica \\
\hline & & 1.1.3 Mangue \\
\hline & 1.2 Floresta Plantada & - \\
\hline \multirow{5}{*}{$\begin{array}{l}2 \text { Formação Natural não } \\
\text { Florestal }\end{array}$} & 2.1 Área Úmida Natural não Florestal & - \\
\hline & 2.2 Formação Campestre & - \\
\hline & 2.3 Outra Formação não Florestal & - \\
\hline & 2.4 Afloramento Rochoso & - \\
\hline & 2.5 Apicum & - \\
\hline \multirow{4}{*}{3 Agropecuária } & 3.1 Pastagem & - \\
\hline & \multirow{2}{*}{ 3.2 Agricultura } & 3.2.1 Cultivo Anual e Perene \\
\hline & & 3.2.2 Cultivo Semiperene \\
\hline & 3.3 Mosaico de Agricultura ou Pastagem & - \\
\hline \multirow{4}{*}{4 Área não vegetada } & 4.1 Praia e Duna & - \\
\hline & 4.2 Infraestrutura Urbana & - \\
\hline & 4.3 Outra área não vegetada & - \\
\hline & 4.4 Mineração & - \\
\hline \multirow{2}{*}{5 Corpo d'Água } & 5.1 Aquicultura & - \\
\hline & 5.2 Rio, Lago e Oceano & - \\
\hline 6 Não observado & - & - \\
\hline
\end{tabular}

Fonte: Adaptado de MapBiomas (2019a, p.18-19). 
Basicamente a cobertura pode ser dividida em cinco classes: floresta, formação natural não florestal, agropecuária, área não vegetada e corpo d'água. Floresta pode ser separada em floresta natural ou plantada, sendo que a floresta natural ainda se subdivide em formação florestal, savânica e mangue. A formação natural que não é de florestas pode ser classificada em área úmida natural não florestal, formação campestre e outra formação não florestal, além do afloramento rochoso e apicum. A agropecuária, por sua vez, subdividese em pastagem e agricultura. Uma terceira subdivisão aparece entre as duas primeiras quando há um mosaico de práticas agropastoris. A agricultura ainda pode ser desagregada em cultivo anual e perene (café, laranja e cacau, por exemplo) e no cultivo semiperene (por exemplo, arroz, feijão, milho, algodão e soja). A área não vegetada compreende as áreas de praia e duna, manchas urbanas, áreas de extração mineral e outra área não vegetada. Por fim, o corpo d'agua pode ser visualizado em aquicultura e uma outra classe com águas superficiais visualizadas em rios, lagos e oceanos.

\section{Análise dos resultados}

A análise dos resultados está subdivida em duas partes. A primeira apresenta os resultados dos conglomerados cross-section; a segunda, os resultados dos conglomerados de séries temporais univariado, considerando a principal transição de uso e cobertura do solo, e os resultados dos conglomerados de séries temporais multivariado, considerando um conjunto de transições relevantes.

\section{1 Resultados da identificação do nível de análise}

A primeira parte do estudo leva em conta as transições entre os tipos de uso e cobertura do solo, no período estudado, de forma líquida. Em outras palavras, compara a mudança de cenário entre os pontos inicial e final de tempo, com o intuito de observar possíveis padrões semelhantes de transformação do uso e cobertura do solo, entre as Unidades da Federação.

A base de dados, já apresentada, do MapBiomas possui níveis hierárquicos quanto aos tipos de uso e cobertura do solo a serem considerados. Dessa forma, o primeiro passo nesse exercício é definir qual nível, ou combinação de níveis, deve ser selecionada para se obter o conjunto de variáveis de homogeneidade (transições entre esses usos/coberturas), a ser utilizado no agrupamento de Unidades da Federação. Na análise inicial dessa questão, 
considerou-se a divisão mais simples de uso e cobertura (nível 1), e calculou-se a transição entre esses possíveis estados, entre 1985 e 2018, como mostra a Tabela 1.

Tabela 1: Transição de uso e cobertura do solo brasileiro, em hectares, entre os anos de 1985 e 2018

\begin{tabular}{|c|c|c|c|c|c|c|c|}
\hline \multirow[b]{2}{*}{$\begin{array}{l}\text { Uso / cobertura } \\
\text { em } 1985\end{array}$} & \multicolumn{7}{|c|}{ Uso / cobertura em 2018} \\
\hline & \begin{tabular}{|l|} 
Não ob- \\
servado
\end{tabular} & Floresta & \begin{tabular}{|l|} 
Form. nat. \\
não florestal
\end{tabular} & Agropecuária & \begin{tabular}{|l|} 
Área não \\
vegetada
\end{tabular} & $\begin{array}{l}\text { Corpo } \\
\text { d'água }\end{array}$ & Total \\
\hline Não observado & 9.816 & 989 & 475 & 456 & 880 & 1.068 & 13.683 \\
\hline Floresta & 496 & 492.038 .386 & 3.931 .489 & 96.533 .981 & 690.696 & 2.198 .317 & 595.393 .365 \\
\hline $\begin{array}{l}\text { Form. natural } \\
\text { não florestal }\end{array}$ & 431 & 4.641 .676 & 42.760 .286 & 10.920 .470 & 365.957 & 753.328 & 59.442 .149 \\
\hline Agropecuária & 140 & 20.706 .172 & 2.713 .428 & 151.749 .818 & 1.688 .313 & 578.843 & 177.436 .713 \\
\hline $\begin{array}{l}\text { Área não vege- } \\
\text { tada }\end{array}$ & 1.485 & 253.718 & 169.053 & 820.707 & 2.053 .491 & 35.993 & 3.334 .447 \\
\hline Corpo d'água & 427 & 1.021 .086 & 449.437 & 640.954 & 72.449 & 13.253 .513 & 15.437 .866 \\
\hline Total & 12.795 & 518.662 .028 & 50.024 .168 & 260.666 .385 & 4.871 .785 & 16.821 .063 & 851.058 .223 \\
\hline
\end{tabular}

Fonte: Dados básicos: MapBiomas (2019b). Elaborado pelos autores.

Os valores contidos na Tabela 1, fora da diagonal principal (a qual está em negrito), referem-se ao quantitativo de área que mudou de estado de uso/cobertura do solo no período de tempo estudado. As maiores transições são de floresta para agropecuária e o seu inverso, totalizando mais de 96 e 20 milhões de hectares, respectivamente. Outra transição vultosa foi a de formação natural não florestal para agropecuária que totalizou quase 11 milhões de hectares. Essa tabela traz duas informações importantes. A primeira é a expressiva diminuição de áreas naturais, sejam florestas ou formações não florestais, em contraposição ao aumento de áreas para a agropecuária. A segunda é que, dado o grande volume de área transicionada na categoria agropecuária, trabalhar exclusivamente nesse nível hierárquico mais agregado pode acarretar perda de informações relevantes. Sendo assim, o mesmo tipo de investigação foi feito agora tendo como base os usos e coberturas do solo contidos no segundo nível do MapBiomas.

Uma vez que as categorias de uso/cobertura do solo no nível 2 passam de 6 para 17, o número de transições entre estados torna-se muito grande e, por isso, essas informações são apresentadas na Tabela A1 do Anexo. É possível observar, com base na referida tabela, que grande parte das áreas convertidas para a categoria "agropecuária" são de pastagens, embora o montante convertido para a agricultura seja também muito expressivo. A área total dessas duas categorias passou de pouco mais de 134 e 23 milhões de hectares para valores acima de 180 e 60 milhões de hectares, respectivamente, entre 1985 e 2018 . Por outro lado, a área de florestas naturais reduziu-se consideravelmente, passando de 592,8 
para 510 milhões de hectares, o que nem de perto foi compensado pelo aumento das áreas de floresta plantada (2,6 para 8,6 milhões de hectares). Há que se destacar também o grande aumento proporcional da infraestrutura urbana, passando de aproximadamente 1,4 para 3,3 milhões de hectares no período.

Dessa forma, optou-se por trabalhar com as categorias do nível 2 para "floresta" (floresta natural e floresta plantada) e "agropecuária" (pastagem, agricultura e mosaico de agricultura ou pastagem). Adicionalmente, na categoria "área não vegetada", separouse infraestrutura urbana das demais subcategorias, devido ao seu expressivo crescimento registrado no período e pela importância da dispersão urbana para a dinâmica ambiental. As categorias "formação natural não florestal" e "corpo d'água" permaneceram agregadas e a categoria "não observada" foi excluída do exercício de agrupamento, uma vez que esta representa falta de informação. Assim, as nove categorias de uso ou cobertura do solo escolhidas são: floresta natural; floresta plantada; formação natural não florestal; pastagem; agricultura; mosaico de agricultura ou pastagem; infraestrutura urbana; demais áreas não vegetadas; e corpo d'água.

Desta forma, são teoricamente $72(9 \times 8)$ transições possíveis entre distintas categorias de uso ou cobertura do solo, as quais serão as variáveis a serem consideradas na análise de cluster. No entanto, na prática alguns tipos de transição são quase inexistentes, por exemplo, floresta plantada e infraestrutura urbana se transformar em corpo d'agua.

\subsection{Resultado dos conglomerados cross-section 1985/2018}

Geralmente as variáveis para análise de conglomerados são normalizadas para evitar que uma delas, por possuir maior variância que as demais, acabe tendo mais importância na hora da formação dos grupos. Nesse caso específico, porém, o valor da transição, área medida em hectares, é justamente a medida da sua importância para o fenômeno que queremos observar. Tomando como base a Tabela 1, por exemplo, é fácil perceber que a transição de mais de 96 milhões de hectares de florestas para práticas agropecuárias possui um impacto muito maior para o meio ambiente do que os 690 mil hectares de florestas que viraram áreas não vegetadas. Assim, o valor das transições em cada UF serão relativizadas pelo tamanho da UF, mas não ocorrerá normalização dos seus valores, fazendo com que as principais transições, em termos de área, tenham maior peso no algoritmo de agregação.

Esses dados então foram submetidos à análise de conglomerados por meio 
da PROC CLUSTER do aplicativo SAS University Edition. A técnica para construção dos grupos foi do tipo hierárquica aglomerativa, ou seja, parte-se de um ponto inicial tal que cada elemento é um cluster, e, a partir daí, são feitas sucessivas agregações. Utilizou-se o método de agrupamento das variâncias mínimas de Ward que é apropriado para variáveis quantitativas, uma vez que tem como base a comparação de vetores de médias entre os possíveis conglomerados formados (MINGOTI, 2005). A Tabela 2 mostra alguns resultados do arquivo de saída do agrupamento.

Tabela 2: Resultados da agregação até a formação do $8^{\circ}$ grupo

\begin{tabular}{|l|l|l|l|l|l|l|l|l|}
\hline Grupo & 1 & 2 & 3 & 4 & 5 & 6 & 7 & 8 \\
\hline R2 & ---- & 0,376 & 0,543 & 0,645 & 0,697 & 0,743 & 0,778 & 0,809 \\
\hline Pseudo t2 & 15,0 & 8,5 & 7,2 & 4,9 & 3,4 & 10,4 & 5,6 & 3,8 \\
\hline
\end{tabular}

Fonte: Elaborado pelos autores.

A primeira linha da Tabela 2 representa o número de grupos formados até determinado momento do algoritmo; já a segunda (R2) é a proporção da variância total contabilizada pelos grupos naquele momento; e a terceira (pseudo t2) é um dos critérios de parada das agregações. A estatística pseudo t2 é interpretada observando-se aumentos súbitos de seu valor, tal que um bom ponto de parada seria com um número de grupos imediatamente posterior a esse aumento. Assim, o aumento da estatística de 3,4 para 10,4 no ponto 6 indica uma formação de 7 grupos, que abarca aproximadamente $78 \%$ da variância total dos dados. A seguir, estão apresentados os grupos de Unidades da Federação formados, com suas características descritas. Cabe ressaltar que a transição mais significativa em termos de área foi a de floresta natural para pastagem, no período de estudo, como mostra o Anexo A. Dessa forma, essa variável acabou tendo maior importância no algoritmo de agrupamento, uma vez que não houve normalização dos dados. Os grupos serão apresentados por conveniência de interpretação e não ordenados pela numeração - que é aleatória - dada pelo SAS.

- Grupo 7: composto somente por Rondônia. Essa Unidade da Federação ficou isolada nesse grupo por ser um outlier na transição de floresta natural para pastagem, dado que aproximadamente $27,6 \%$ do total da área da UF passou do primeiro estado para o segundo, no período estudado.

- Grupo 3: composto por Pará, Tocantins, Maranhão, Mato Grosso do Sul, Mato Grosso e Goiás. Composto pelas 6 UFs que, depois de Rondônia, apresentaram 
as maiores transições de floresta natural para pastagem, compreendendo entre $13,2 \%$ e $19,0 \%$ de suas áreas totais.

- Grupo 2: composto por Acre, Ceará, Paraíba, Pernambuco, Alagoas, Sergipe e Bahia. Composto pelas 7 UFs com as maiores transições, depois dos grupos 3 e 7 , de floresta natural para pastagem, compreendendo entre $7,8 \%$ e $12,4 \%$ de suas áreas totais.

Os próximos grupos apresentados tiveram transições mais modestas de floresta natural para pastagem e foram discriminados por outras características. São eles:

- Grupo 4: composto por Espírito Santo, São Paulo e Paraná. Essas UFs apresentaram pequenas transições de floresta natural para pastagem $(0,8 \%$ a 1,8\% de suas áreas totais), mas apresentaram as transições mais expressivas de pastagem para agricultura (8,0\% a $18,5 \%$ de suas áreas totais). Observaram-se também valores acima da média tanto para transição de pastagem e mosaico de agricultura/pastagem (4,6\% a $8,1 \%$ de suas áreas totais) quanto para a transição inversa ( $2,4 \%$ a $4,0 \%$ de suas áreas totais)

- Grupo 1: composto por Amazonas, Roraima, Amapá e Piauí. Essas UFs não só apresentaram pequenas transições de floresta natural para pastagem $(0,8 \%$ a 4,4\% de suas áreas totais) como também tenderam a apresentar valores abaixo da média ou até mesmo nulos para as outras principais transições observadas no período.

- Grupo 5: composto por Rio Grande do Norte, Minas Gerais, Rio de Janeiro, Santa Catarina e Distrito Federal. Composto por UFs que apresentaram valores modestos, mas, em média, um pouco maiores que os grupos anteriores para a transição de floresta natural para pastagem (1,4\% a 6,8\% de suas áreas totais). Ao contrário do grupo 1 e 4, não se destacaram com valores mais baixos ou mais altos para as demais transições.

- Grupo 6: composto somente pelo Rio Grande do Sul. Essa Unidade da Federação ficou isolada nesse grupo por ser um outlier tanto por seu valor baixo em transição de floresta natural para pastagem ( $0,3 \%$ de sua área total), dado que é um estado pouco florestado, quanto pelos seus altos valores nas transições de formação natural não florestal para agricultura (9,1\% de sua área total) e de agricultura para pastagem (2,7\% de sua área total). 
A figura 1 apresenta os grupos de UFs descritos no mapa brasileiro. Adicionalmente o dendograma com a formação dos grupos se encontra no Anexo B.

Figura 1: Grupos das transições de uso e cobertura do solo nas unidades da federação do Brasil a partir do clustering cross-section - de 1985 para 2018

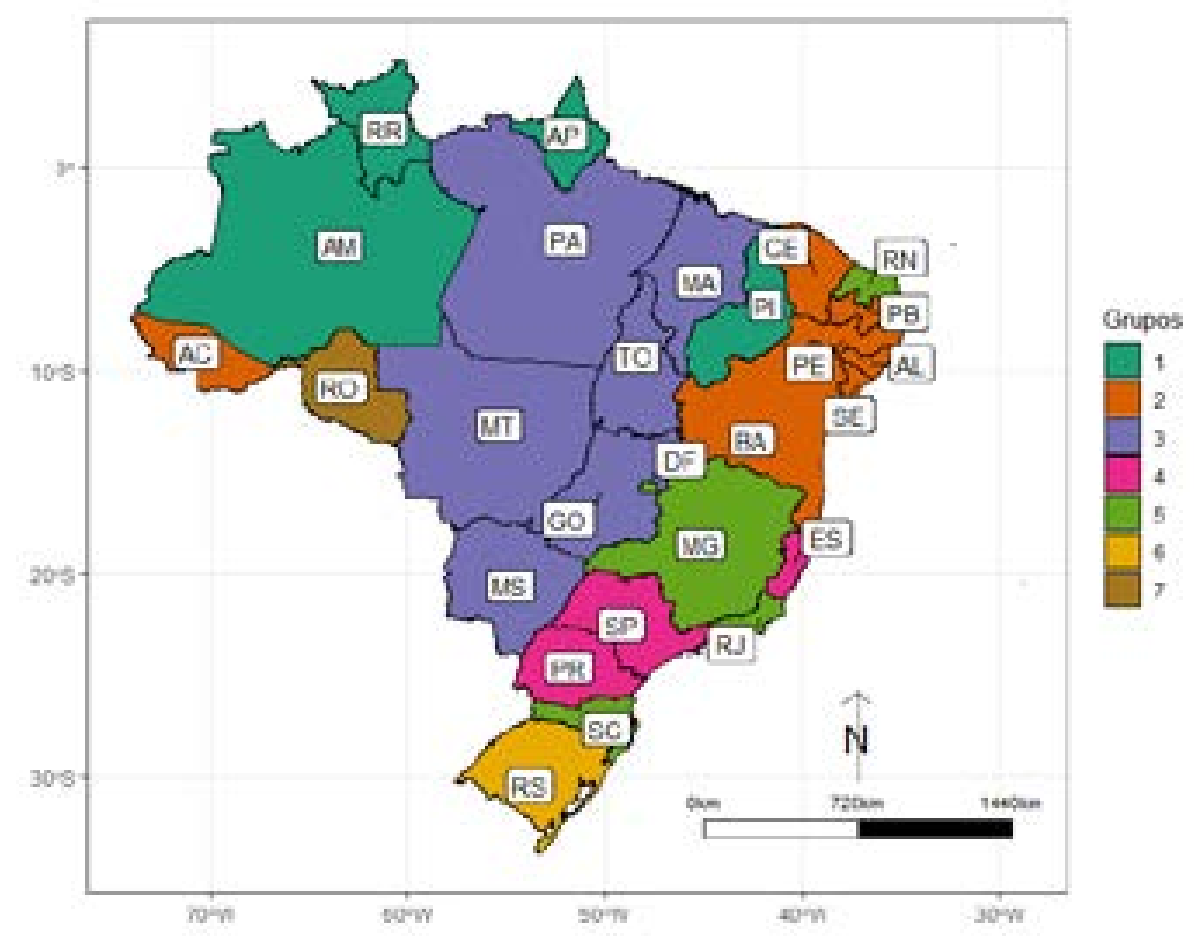

Fonte: Elaborado pelos autores.

É interessante notar, com base na figura 1, que apesar de não haver quaisquer restrições ou incentivos em termos de contiguidade ou vizinhança dos elementos a serem agregados, UFs em mesmos grupos tenderam a apresentar certa similaridade espacial. Isso é decorrente, pelo menos em parte, dos biomas às quais elas estão inseridas que influenciam nos tipos de transições observadas.

Esse primeiro estudo mostrou que o panorama da mudança do uso e cobertura do solo, entre 1985 e 2018, pode ser resumido a um pequeno conjunto de transições mais importantes. De um lado, as regiões Centro-Oeste, Nordeste e parte da região Norte que experimentaram a substituição de relevante parte de seus territórios cobertos por florestas naturais para áreas de pastagem. De outro, UFs localizadas nas regiões Sul e Sudeste que tiveram aumentos proporcionais maiores de áreas destinadas a agricultura, sejam elas oriundas de formações naturais não florestal ou pastagens, por exemplo. Essa análise inicial possibilita, então, destacar um conjunto mais restrito de transições relevantes para serem 
trabalhadas de forma longitudinal, ou seja, as transições ano a ano. Dessa forma, suas trajetórias durante o período de estudo também podem ser levadas em conta.

5.3 Resultado dos conglomerados de séries temporais 1985-2018: principal transição

A análise anterior pode ser expandida para identificação de conglomerados da série de maior relevância - a transição de floresta natural para pastagem. Para isso, foram consideradas 33 informações no tempo que representam transições a cada par de ano: 1986 em relação a 1985, 1987 em relação a 1986 e assim por diante. O espaço considera um conjunto total de 27 Unidades da Federação, formando um painel com 891 dados.

Da mesma forma que nos procedimentos anteriores não se realizou a normalização das séries, sendo que estas foram transformadas apenas em relação ao tamanho da área total da respectiva Unidade da Federação, ou seja, as séries utilizadas são a proporção de transição em relação a área total da UF.

Empregou-se o pacote dtwclust (GIORGINO, 2009) no software $R$ para realizar o cluster de séries temporais. Optou-se pelo método hierárquico divisivo com ligação pelo vizinho mais distante e a distância calculada pela técnica Dynamic Time Warping (DTW), conforme a seção de metodologia. O ponto inicial considera que todas as séries estão em um único cluster e, a partir disso, inicia a desagregação até a situação em que cada série é apenas um cluster isolado. Cinco grupos apresentam-se naturalmente e possuem características bastante definidas que os agrupam. O dendograma apresenta a formação dos grupos no Anexo B. Como trata-se de um cluster de séries temporais, tanto os níveis quanto as inclinações comuns colaboraram para o agrupamento das UFs em um mesmo cluster. Vale ressaltar que os grupos serão apresentados por conveniência de interpretação e não ordenados pela numeração - que é aleatória - dada pelo pacote do $R$.

- Grupo 1: composto por Rondônia, Pará, Tocantins, Mato Grosso e Goiás. Apresentaram patamares altos no início da série (entre 1,0\% e 1,5\%), seguido de uma redução das proporções de floresta natural transformadas em pastagem em relação ao total de suas áreas mantendo um certo nível de estabilidade em torno dos $0,6 \%$ ao ano.

- Grupo 5: composto por Sergipe, Bahia, Ceará, Paraíba, Pernambuco, Rio Grande do Norte, Alagoas, Minas Gerais e Mato Grosso do Sul. Apresentaram patamares altos no início da série seguido de uma redução, sendo ainda mais estável que o grupo 1, em um nível constante abaixo de 0,5\%. 
- Grupo 4: composto somente por Maranhão. Apresentou patamar alto no início da série, como o grupo 1 e 5, porém manteve-se em um média desse tipo de transição em 1,5\% do seu território, destacando um expressivo aumento nos últimos anos alcançando quase 3\% no ano de 2018 comparado a 2017. Ressaltase ainda que esse estado não apareceu como outlier na análise de conglomerados cross-section. Na análise da seção "Resultado dos conglomerados cross-section 1985/2018", o Maranhão integrou o grupo 3 que apresentaram as maiores transições de floresta natural para pastagem, no entanto aqui ficou evidenciado que sua trajetória se diferencia dos demais de tal maneira que não o agrupo com nenhuma outra UF. Esse aspecto ressalta a relevância e a complementariedade das metodologias aqui adotadas.

Os próximos grupos apresentados tiveram transições em menores magnitudes de floresta natural para pastagem e o comportamento posterior ao período inicial da série os discriminam. São eles:

- Grupo 2: composto por Roraima, Acre, Piauí e Distrito Federal. Apresentaram menores proporções de transição de floresta natural para pastagem em relação aos grupos anteriores mencionados (abaixo de 0,5\%). Após o período inicial com uma média mais alta comparada a toda sua série, apresentou uma média de comportamento bastante errática variando entre $0,25 \%$ a um pouco mais de $0,4 \%$,

- Grupo 3: Rio de Janeiro, São Paulo, Espírito Santo, Paraná, Rio Grande do Sul, Santa Catarina, Amazonas e Amapá. O grupo com as menores proporções de transição de floresta natural para pastagem (abaixo de 0,2\%, em média). Após o período inicial, apresentou tendência negativa até estabilizar um pouco acima de $0,05 \%$ e elevar-se nos últimos anos.

Esses comportamentos descritos anteriormente estão representados pelo padrão médio das séries temporais presentes em cada grupo na figura 2. 
Figura 2: Trajetórias das centroides das séries temporais de transição de floresta natural para pastagem por grupos (\%) - pares de transição 1985/1986 a 2017/2018
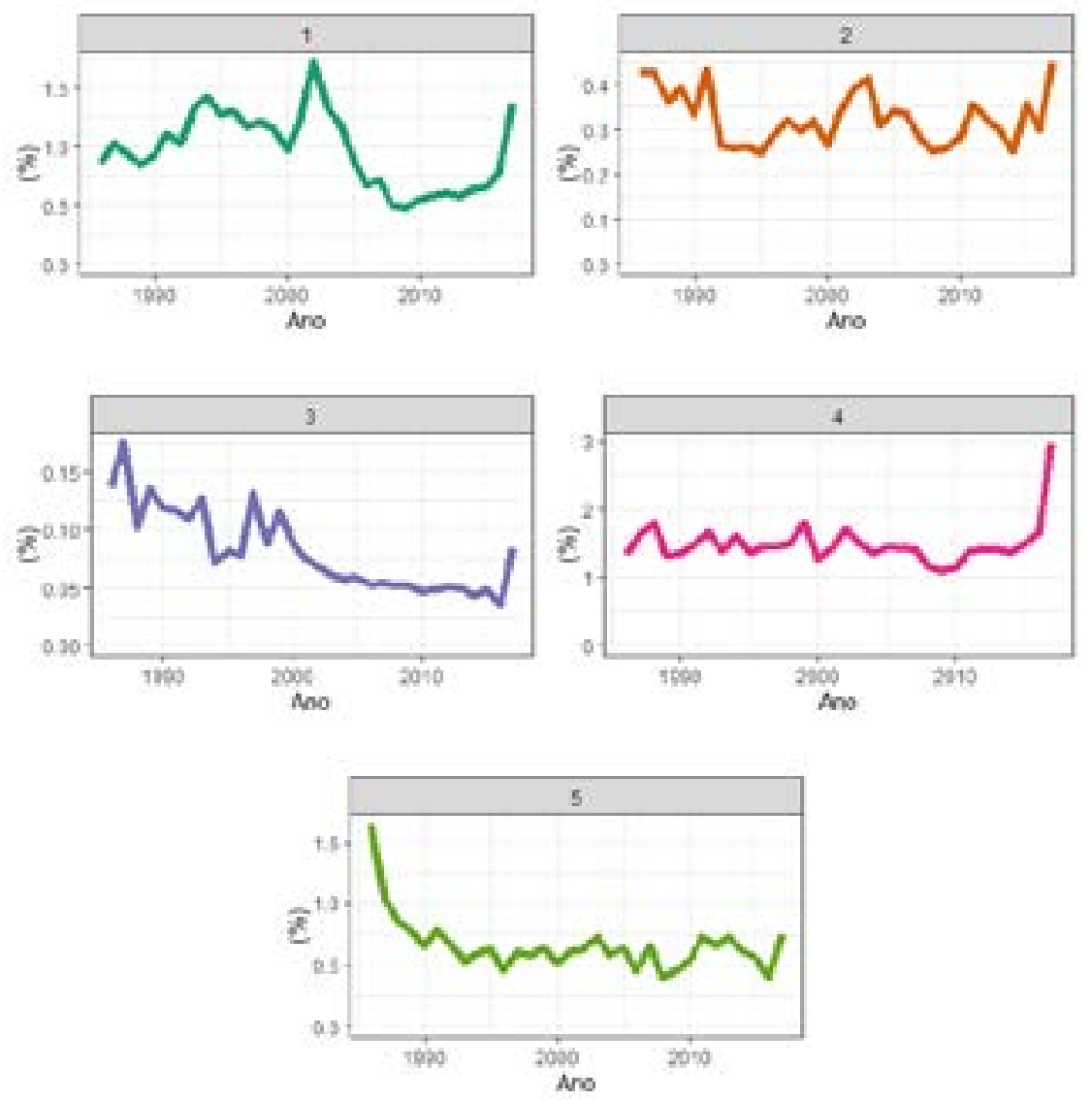

Fonte: Elaborado pelos autores. NOTA: Os anos no eixo das ordenadas representam os pares de transição 1985/1986 a 2017/2018, sendo o primeiro ano indicado no eixo.

Em síntese, o padrão identificado pela dinâmica da transição da cobertura floresta natural para o uso em pastagens revelou que, nos anos iniciais, todos apresentaram elevação, seguido com uma estabilização dessa proporção, com exceção apenas de um grupo que decresceu no período. Essa estabilização foi mais errática para alguns do que para outros, tendo, nos períodos finais, tendência de elevação para todos os grupos.

A figura 3 apresenta, em um mapa, os grupos de cada UF conforme os resultados apresentados anteriormente. Identificou-se que, em termos dos pontos colaterais, há um "cinturão" do sudoeste a nordeste (grupos 1, 4 e 5), excluindo o Distrito Federal e Piauí, que apresentaram níveis mais elevados de transição de floresta natural para pastagem, sendo que diminui essas magnitudes a sudeste (todos do grupo 5) e também aqueles do grupo 3 , únicos que apresentaram tendências negativas mais acentuadas para esse tipo de transição. Esses resultados convergem com os estudos sobre o arco do desflorestamento, Domingues 
e Bermann (2012), por exemplo, apontaram que uma das principais atividades responsáveis pelo desmatamento da mata nativa e que tem avançado sobre o arco do desflorestamento é a pecuária.

Figura 3: Grupos da transição de floresta natural para pastagem nas unidades da federação do Brasil a partir do clustering de séries temporais - 1985 a 2018

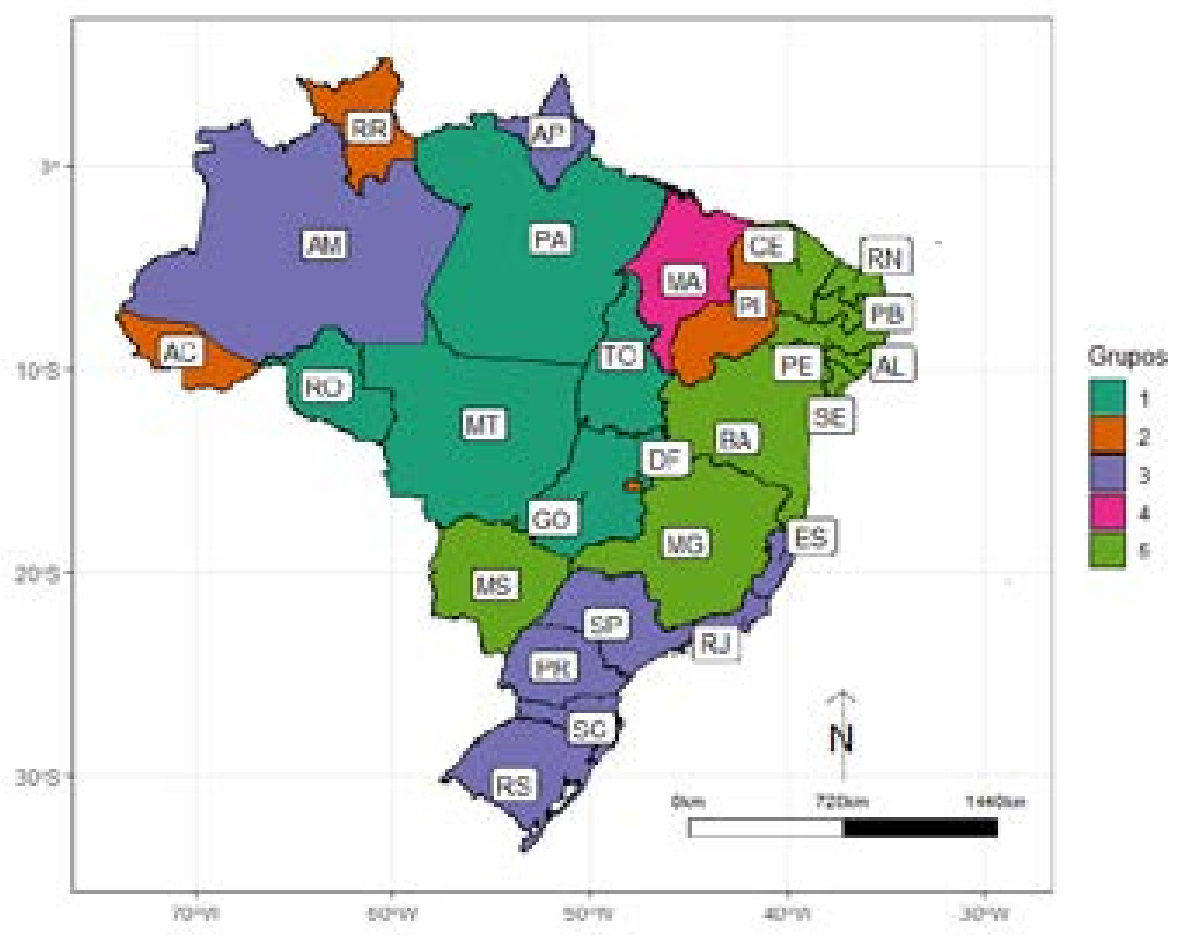

Fonte: Elaborado pelos autores.

Vale ressaltar que existe uma aproximação desse "cinturão" sudoeste-nordeste com os biomas Pantanal, Cerrado e Caatinga e a faixa do bioma Amazônia mais próxima do Cerrado; o que o presente estudo acrescenta é que o ritmo ainda é elevado para os grupos 1 e 4 e em um menor nível para o grupo 5, sendo ainda menor para o grupo 2 e com tendência de queda para o grupo 3. Apesar do aumento verificado em todos as UFs nos últimos anos, em especial 2017/2018. Destaca-se também os resultados apontados na literatura sobre a região do Cerrado denominada Matopiba, englobando parte do Norte-Nordeste brasileiro (Maranhão, Tocantins, Piauí e Bahia), que vem sendo incorporada ao agronegócio e se consolidando como uma relevante fronteira agrícola (BOLFE et al., 2016). 
5.4 Resultado dos conglomerados de séries temporais 1985-2018: 15 principais transições

Pode-se ainda ampliar a análise para considerar todas as séries, os 72 tipos de transição, no entanto a grande quantidade de zeros não agregaria informações para gerar os resultados, sendo não recomendado esse tipo de procedimento. Porém é possível considerar aquelas transições mais relevantes (15 delas), indicadas pelas setas representadas pela figura 4 e apontadas pelos resultados da seção "Resultado dos conglomerados cross-section 1985/2018". O painel multivariado passa a ter 15 séries para cada uma das 27 UFs em 33 pontos do tempo, resultando em um total de 13.365 dados.

Figura 4: 15 principais transições do uso e cobertura do solo no Brasil (1985/2018)

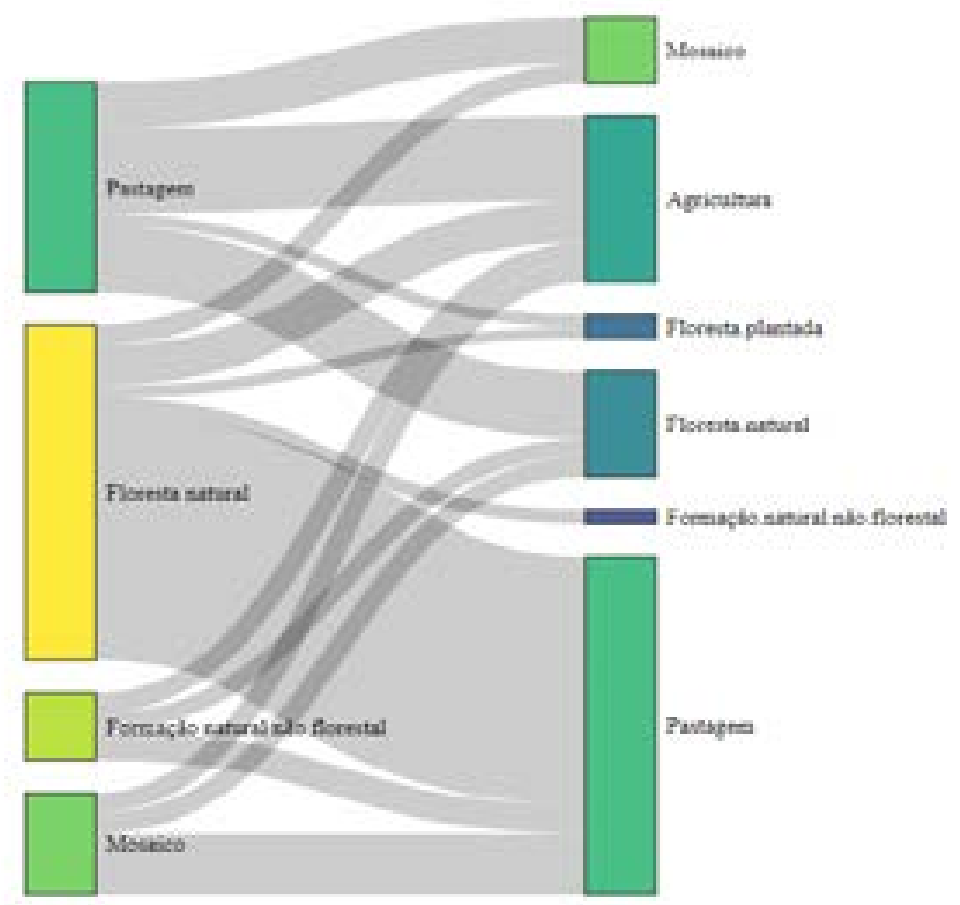

Fonte: Elaborado pelos autores.

O clustering, considerando as 15 principais séries, identificou sete grupos que podem ser separados em dinâmicos (vários tipos de transições se destacaram) e concentrados (poucas transições se sobressaem). Esses últimos são:

- Grupo 1: composto por Rondônia (11), Acre (12), Amazonas (13), Roraima (14), Pará (15), Amapá (16), Tocantins (17), Maranhão (21), Piauí (22) e Sergipe (28). 
Apresentaram principalmente mudanças de transição de floresta natural para pastagem (com dinâmicas diferentes entre eles) ao mesmo tempo em que também se destacaram as transições de floresta natural para formação natural não florestal.

- Grupo 2: composto por Ceará (23), Rio Grande do Norte (24) e Alagoas (27). Como no grupo 1, também se destacou a transição de floresta natural para formação natural não florestal, e vice-versa (em menor patamar), no entanto em patamares bem mais elevados (superior a 0.5\%), além dos destaques de transformar a floresta natural em agricultura e a pastagem em mosaico.

- Grupo 3: composto por Paraíba (25) e Pernambuco (26) e Distrito Federal (53). Destaque para as transições entre floresta natural e pastagem, o que o aproxima do grupo 1, porém também se destaca a floresta natural se transformando em mosaico e o retorno de formação natural não florestal para floresta natural.

Os próximos grupos apresentaram uma dinâmica maior no sentido de ocorrer mais diversidade dos tipos de transições:

- Grupo 4: composto por Bahia (29) e Minas Gerais (31). Esse grupo apresentou algum percentual entre todas as 15 transições consideradas. Destaque para as altas transições entre floresta natural e pastagem, além de suas transformações em agricultura e o mosaico de áreas agropastoris.

- Grupo 5: composto por Espírito Santo (32), Rio de Janeiro (33), São Paulo (35), Paraná (41) e Santa Catarina (42). O principal destaque desse grupo são as transformações da pastagem em mosaico e mosaico em pastagem em proporções similares ao longo do tempo, além de níveis de pastagem se tornando agricultura e o processo de floresta natural se tornar mosaico e viceversa.

- Grupo 6: composto apenas por Rio Grande do Sul (43). A transformação da formação natural não florestal em agricultura é o que diferencia esse estado dos demais mantendo-o como outlier em um único grupo, nenhuma outra Unidade da Federação apresentou taxas de transições desse tipo entre 0,75\% e 1,25\% ao ano. Vale ressaltar que o estado também apresentou várias outras transições, porém com percentuais menores a $0,5 \%$ ao ano.

- Grupo 7: composto por Mato Grosso do Sul (50), Mato Grosso (51) e Goiás 
(52). As transições que envolvem pastagem são as com maiores proporções em média, tanto floresta natural se tornando pastagem quanto pastagem se tornando agricultura e floresta natural. Sawyer (2002) já havia afirmado sobre o Centro-Oeste provavelmente ser a região mais heterogênea de todas as regiões do Brasil não somente sob o ponto de vista ecológico.

A figura 5 apresenta em mapa os grupos de cada UF conforme os resultados apresentados anteriormente.

Figura 5: Grupos das 15 principais transições do uso e cobertura do solo nas unidades da federação do Brasil a partir do clustering se séries temporais - 1985 a 2018

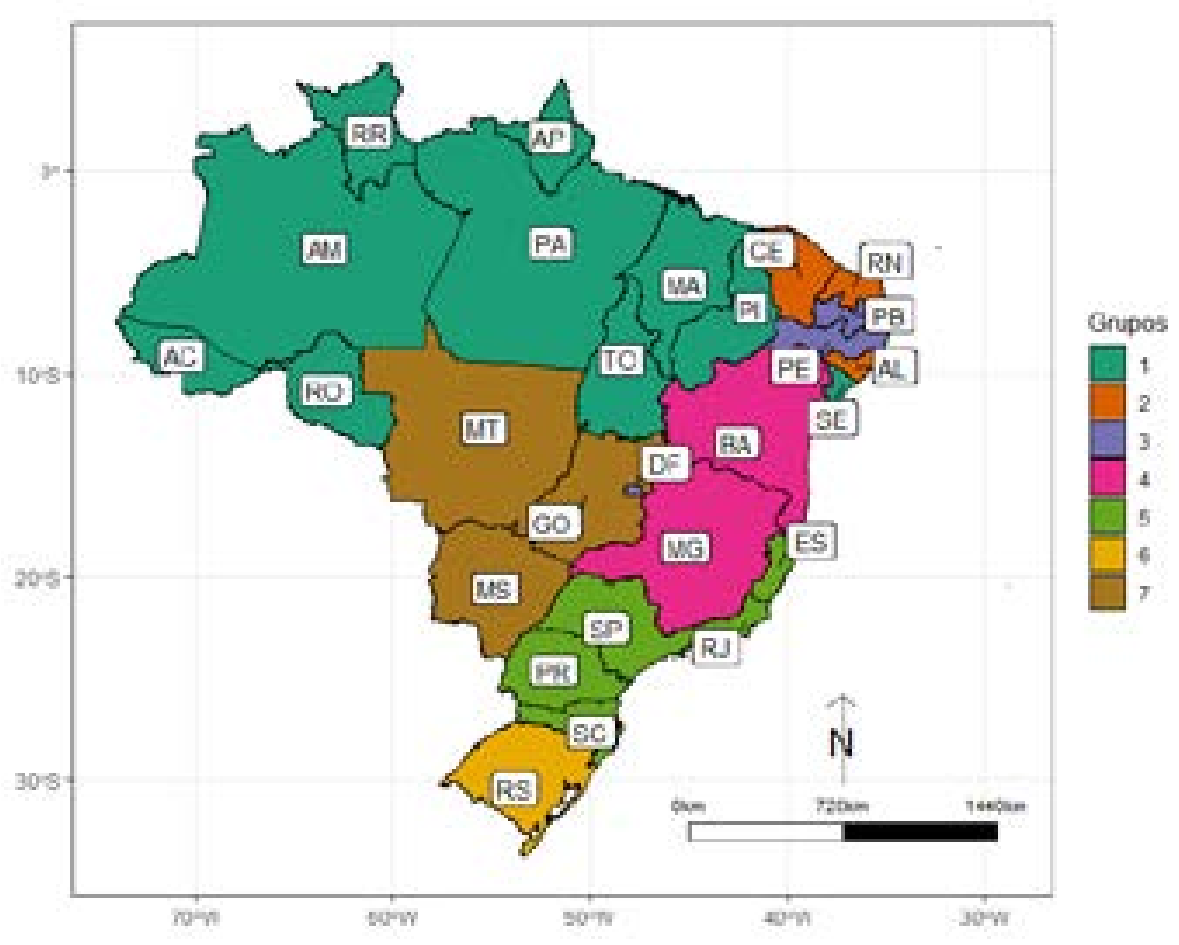

Fonte: Elaborado pelos autores.

O clustering das 15 principais transições da cobertura e do uso revelou um caráter regional dos grupamentos sendo que aqueles do mesmo grupo se apresentam como vizinhos, com exceção do Distrito Federal, Sergipe e Alagoas. 


\section{Considerações finais}

Com o objetivo de identificar as diferenciações espaço-temporais da cobertura e uso do solo no território brasileiro, utilizando recorte político-administrativo das Unidades da Federação, o estudo empregou duas abordagens para considerar o tempo e o espaço na análise. A primeira considerou a comparação das transições do uso e cobertura do solo entre um ponto inicial (1985) e um ponto final (2018), permitindo evidenciar o montante final das alterações do solo brasileiro. A segunda considerou a dinâmica entre os anos de 1985 a 2018, permitindo verificar como ocorreram as trajetórias das mudanças evidenciadas na primeira análise.

As seguintes constatações gerais foram encontradas: (a) a transformação de floresta natural para pastagem representou a principal transição do solo brasileiro, principalmente nas regiões Centro-Oeste, Nordeste e parte da região Norte; (b) a região Norte e parte do Nordeste concentraram mais em tipos específicos, como as transições entre floresta natural se transformando em pastagem e outras transformações com formação natural não florestal; (c) os estados litorâneos da Bahia até o Rio Grande do Sul, e também Minas Gerais, apresentaram uma dinamicidade em termos dos tipos das transições ocorridas, em especial aquelas transições que envolvem atividades agropastoris; (d) a região Centro-Oeste, excluindo o Distrito Federal, também apresentou uma grande quantidade de transições com destaques para aquelas envolvendo pastagem; (e) os biomas, em parte, influenciam nos tipos de transições observadas, principalmente no Rio Grande do Sul, mas as trajetórias se diferenciam; (f) as trajetórias da transição de floresta natural para pastagem podem ser entendidas como um "cinturão" sudoeste-nordeste em relação ao centro do Brasil, sendo que reduz as magnitudes à medida que se caminha para direita e esquerda do "cinturão", salvo algumas exceções como Distrito Federal e Piauí; (g) Rio de Janeiro, São Paulo, Espírito Santo, Paraná, Rio Grande do Sul, Santa Catarina, Amazonas e Amapá apresentaram tendências negativas da transição de floresta natural para pastagem mais acentuadas que os demais; (h) no entanto todas as UFs apresentaram aumentos na transformação de floresta natural para pastagem nos últimos anos; (i) mediante a complementariedade das metodologias adotadas, foi possível identificar, por exemplo, o caso do Maranhão que integra o grupo de UFs com as maiores transições de floresta natural para pastagem, no entanto é um outlier em termos de sua trajetória que o diferenciou de todas as demais, ressaltando assim a complementariedade das metodologias aqui adotadas. 
O presente estudo reconhece que análises micro, no sentido de optarem por escalas reduzidas ou até mesmo por estudos específicos de biomas, agregam mais detalhamento para o entendimento das causas das mudanças, dado que consegue aproximar cada vez mais das particularidades locais, das ações antrópicas. No entanto o recorte políticoadministrativo escolhido pelo artigo identificou que ações podem ser mais intensivamente cobradas do poder público do Norte, bem como em parte do Nordeste, pelo montante e pelo ritmo principalmente das transições envolvendo a floresta natural e a formação natural não florestal. Além da maior atenção para a dinâmica produtiva envolvendo as atividades agropastoris e o repentino aumento da transição de floresta natural para pastagem nos últimos dois anos. Atenção esta que se insere nas discussões do uso ou manejo sustentável dos recursos naturais.

Os avanços das atividades agropastoris expõem que a relação com o mercado ainda se concentra na busca frenética de commodities. Little (2015), em sua discussão sobre desenvolvimento territorial sustentável, apontou uma potencialidade ao falar sobre o estabelecimento de novas relações com o mercado, o que, na presente análise macro realizada, não se evidenciou, dado que, nos anos mais recentes, o que se verifica é o aumento da produção agropastoril em detrimento das florestas naturais.

A pressão pelo alcance de patamares cada vez mais altos de produção e consumo, conforme Sawyer (2002), continuam atuantes e até mesmo as Unidades da Federação que apresentavam, por exemplo, tendência negativa na transição de floresta natural para pastagem sofreram inflexão nos anos de 2017 e 2018, revelando que as medidas ambientais necessitam ser efetivas para barrar o agravamento da situação ambiental no país. Em nível internacional, há muito ainda a ser discutido na controversa atual agenda, as ODS, no que eles denominam como crescimento econômico sustentável.

Ressalta-se ainda que o estudo buscou os aspectos gerais. No entanto o método de análise aqui empregado não impede de ser usado sob o ponto de vista menos agregado como identificações das trajetórias espaço-temporais de transições específicas, como as manchas da urbanização, transformações de corpos d'agua ou estudos específicos sobre mangue, agricultura, zonas costeiras, entre outros. Existem muitas possibilidades de expansão da análise aqui empregada. Como exemplo, um próximo estudo poderia analisar quais políticas, programas, planos e ações foram implementadas pelas Unidades da Federação, no período 1985-2018, e como isso se refletiu nas transições de uso e cobertura do solo, bem como, conforme afirmado por Vieira, Santos Junior e Toledo (2014), sobre sinalizações 
antagônicas; estas poderiam ter verificadas a sua existência entre as medidas das UFs e as medidas federais, especialmente após 2017.

\section{Referências}

AGHABOZORGI, S.R.; SHIRKHORSHIDI, A.S.; WAH, T.Y. Time-series clustering - A decade review. Information Systems, n. 53, p. 16-38, 2015. DOI: https://doi.org/10.1016/j.is.2015.04.007.

AGUIAR, A.P.D.; Modelagem de mudanças de uso e cobertura do solo na Amazônia: Questões Gerais. In: Introdução à Modelagem Dinâmica Espacial. 2003. Disponível em: <http://www.dpi.inpe.br/cursos/ tutoriais/modelagem/ >.

BATISTELLA, M.; MORAN, E.F.; A heterogeneidade das mudanças de uso e cobertura das terras na Amazônia: em busca de um mapa da estrada. In: Dimensões Humanas da Biosfera-Atmosfera na Amazônia. 1ed. 2007. Disponível em:<https://www.alice.cnptia.embrapa.br/handle/doc/17674>.

BECKER, B. K. Revisão das Políticas de Ocupação Amazônica: é possível identificar modelos para projetar cenários? Parcerias Estratégicas (Brasília), Brasília, v. 12, p. 135-159, 2001. Disponível em:< http://seer.cgee. org.br/index.php/parcerias_estrategicas/article/view/178>.

BOLFE, E.L.;VICTORIA, D.C.; CONTINI, E.; SILVA, G.B.S.; SPINELLI-ARAUJO, L.; GOMES, D. Matopiba em crescimento agrícola aspectos territoriais e socioeconômicos. Revista de Política Agrícola, v. 12, p. 39-62, 2016. Disponível em: <https://ainfo.cnptia.embrapa .br/digital/bitstream/item/160156/1/Matopiba-em-crescimento-agricola. pdf $>$.

BRASIL. [Constituição (1988)]. Constituição da República Federativa do Brasil: promulgada em 5 de outubro de 1988.

BRIASSOULIS, H. Analysis of Land Use Change: Theoretical and Modeling Approaches. Web Book of Regional Science. Regional Science Institute. West Virginia University. 2019. Disponível em: < https://researchrepository. wvu.edu/rri-web-book/3/>.

COMISSÃO MUNDIAL SOBRE MEIO AMBIENTE E DESENVOLVIMENTO. Nosso futuro comum. Rio de Janeiro: Editora Fundação Getúlio Vargas, 1991.

CÔRTES, J.C.; DANTONA, A.O. Dinâmicas no uso e cobertura da terra: perspectivas e desafios da Demografia. Revista Brasileira de Estudos de População, Rio de Janeiro, v. 31, n.1, p. 191-210, jan./jun. 2014. DOI: http:// dx.doi.org/10.1590/S0102-30982014000100011.

D'ANTONA, A.O.; CAK, A.D.; VANWEY, L.K. Efeitos da escala da análise em estudos de mudança da cobertura da terra entre Santarém e Altamira, no Pará, Brasil. In: HOGAN, D. J. (Org.). Dinâmica populacional e mudança ambiental: cenários para o desenvolvimento brasileiro. Campinas: Núcleo de Estudos de População-Nepo/ Unicamp, 2007, p. 87-113.

DOMINGUES, M.S.; BERMANN, C. O arco de desflorestamento na Amazônia: da pecuária à soja. Ambiente e Sociedade (Campinas), v. 15, p. 1-22, 2012. DOI: http://dx.doi.org/10.1590/S1414-753X2012000200002.

EHRLICH, P.R. The population bomb. New York, NY: Oxford University Press, 1968.

FERNANDES, M.R.M.; MATRICARDI, E.A.T;; ALMEIDA, A.Q.; FERNANDES, M.M. Mudanças do Uso e de Cobertura da Terra na Região Semiárida de Sergipe. Floresta e Ambiente; v. 22, n.4, p. 472-482. 2015. DOI: http://dx.doi. org/10.1590/2179-8087.121514. 
LIAO, T.W. Clustering of Time Series Data-a Survey. Pattern Recognition. v. 38, n.11, p. 1857-74. 2005. DOI: https://doi.org/10.1016/j.patcog.2005.01.025.

LITTLE, P.E. Desenvolvimento territorial sustentável: desafios e potencialidades para o século XXI. Guaju, Matinhos, v.1, n.2, p. 127-143, jul./dez. 2015. DOl: http://dx.doi.org/10.5380/guaju.v1i2.45039

GIORGINO, T. Computing and Visualizing Dynamic Time Warping Alignments in R: The dtw Package. Journal of Statistical Software, n. 31, v.7, p. 1-24. 2009. DOI: http://dx.doi.org/10.18637/jss.v031.i07.

HARDIN, G. The tragedy of the commons. Science, n. 162, 1968. DOI: 10.1126/science.162.3859.1243

MAPBIOMAS. MapBiomas General “Handbook": Algorithm Theoretical Basis Document (ATBD) - collection 4, v. 2, dez. 2019a.

MAPBIOMAS. Coleção 4 da série anual de mapas de cobertura e uso do solo. 2019b. Disponível em: < https://mapbiomas.org/estatisticas>.

MEADOWS, D.H.; MEADOWS, D.L.; RANDERS, J.; BEHRENS III, W.W. Limites do Crescimento: Um relatório para o projeto do Clube de Roma sobre o dilema da humanidade. São Paulo: Editora Perspectiva, 1972.

MINGOTI, S.A. Análise de dados através de estatística multivariada: uma abordagem aplicada. Belo Horizonte. Editora UFMG. 2005.

MINISTÉRIO DO MEIO AMBIENTE. Dinâmica populacional, urbanização e meio ambiente: subsídios para o Rio+20. Série população e desenvolvimento sustentável. Brasília: UNFPA-Fundo de População das Nações Unidas, 2015. Disponível em:< https://brazil.unfpa.org/sites/default/files/pub-pdf/urbanismo1_0.pdf >.

NEVES, L.V.; DEUS, L.A.B.; JÚNIOR, A.C.S.O; FERNANDES, M.C. Mudanças de Uso e Cobertura da Terra e Áreas Suscetíveis à Inundação - Estudo de Caso do Município de Duque de Caxias/RJ. Revista do Departamento de Geografia - v. 37. 2019. DOI: https://doi.org/10.11606/rdg.v37i0.149051.

NOBRE, M.; Carvalho, M.C. (org.) Desenvolvimento Sustentável: a Institucionalização de um Conceito. IBAMA, 2002.

PEBLEY, A.R.; Demography and the environment. Demography, v.35, n.4, p.377-89, 1998. DOI: https://doi. org/10.2307/3004008.

SAKOE, H.; CHIBA, S. A dynamic programming approach to continuous speech recognition. Proceedings of the Seventh International Congress on Acoustics v. 3, p.65-69, 1971. Disponível em:< https://www.irit. $\mathrm{fr} / \sim$ Julien.Pinquier/Docs/TP_MABS/res/dtw-sakoe-chiba78.pdf >.

SAKOE, H.; CHIBA, S. Dynamic programming algorithm optimization for spoken word recognition. IEEE Transactions on Acoustics, Speech, and Signal Processing. n.26, v.1, p. 43-49, 1978. DOI: 10.1109/ TASSP.1978.1163055.

SAWYER, D. População, meio ambiente e desenvolvimento sustentável no Cerrado. 2002. Disponível em:< https://www.researchgate.net/publication/267773958_Populacao_Meio_Ambiente _e_Desenvolvimento_ Sustentavel_no_Cerrado>.

SOUZA, A.A.; GALVÃO, L.S.; Trajetórias de mudança no uso e cobertura da terra e seu impacto na temperatura da superfície modis em áreas de cerrado. Anais do XIX Simpósio Brasileiro de Sensoriamento Remoto. INPE. Santos-SP. 2019. Disponível em: <https://proceedings.science/sbsr-2019/papers/trajetorias-demudanca-no-uso-e-cobertura-da-terra-e-seu-impacto-na-temperatura-de-superficie-modis-em-areas-decerrado>. 
VEIGA, J.E. A Primeira Utopia do Antropoceno. Ambiente e Sociedade, São Paulo, v. 20, n. 2, p. 227-246, 2017. DOI: https://doi.org/10.1590/1809-4422asocex002v2022017.

VIEIRA, I; SANTOS JUNIOR, R.;TOLEDO, P.Dinâmicas produtivas, transformações no uso da terra e sustentabilidade na Amazônia. In: DIFFERT, N; CARDOSO, M.; MAGALHÃES; LASTRES, H. (Orgs). Um olhar territorial para o desenvolvimento: Amazônia. Rio de Janeiro: BNDES, 2014, p. 374-395. Disponível em: < https://web.bndes. gov.br/bib/jspui/handle/1408/15060 >. 


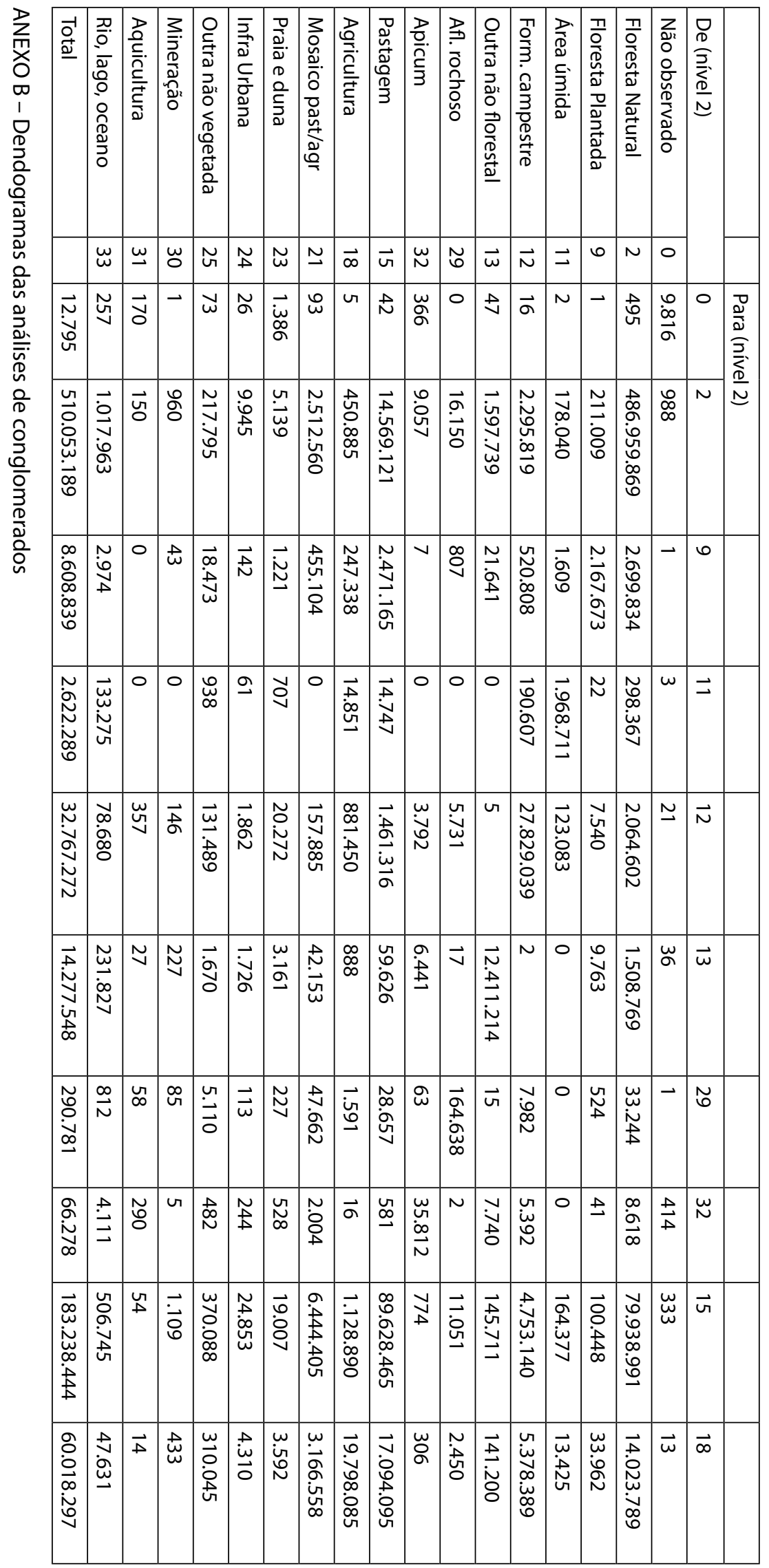




\begin{tabular}{|c|c|c|c|c|c|c|c|c|c|c|c|c|c|c|c|c|c|c|}
\hline $\begin{array}{l}\vec{v} \\
\overrightarrow{0}\end{array}$ & $\mid \begin{array}{l}\infty \\
\infty \\
\stackrel{1}{+} \\
\infty\end{array}$ & \pm & 次 & $\begin{array}{l}\text { U. } \\
\stackrel{\vec{B}}{\mathrm{~g}}\end{array}$ & $\begin{array}{l}\vec{a} \\
\overrightarrow{\hat{Q}} \\
0\end{array}$ & $\begin{array}{l}\tilde{O} \\
\dot{\omega} \\
\hat{U}\end{array}$ & 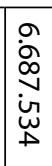 & $\begin{array}{l}\vec{Q} \\
\stackrel{\sim}{\sim} \\
\vec{N}\end{array}$ & 岕 & 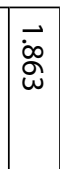 & 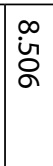 & $\begin{array}{l}\stackrel{N}{\vec{A}} \\
\stackrel{\vec{D}}{ }\end{array}$ & $\stackrel{\underset{\sim}{N}}{\underset{\sim}{\sim}}$ & - & & 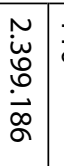 & $\overrightarrow{\vec{o}}$ & $\sim$ \\
\hline$\vec{\Omega}$ & $\mid \begin{array}{l}\vec{v} \\
\dot{\delta} \\
\stackrel{0}{0}\end{array}$ & $\underline{\omega}$ & $\vec{\omega}$ & $\begin{array}{l}i \\
i \\
\sigma\end{array}$ & $\underset{\sim}{\mathbb{N}}$ & $\begin{array}{l}\sim \\
\infty \\
\stackrel{\infty}{0} \\
\stackrel{0}{0}\end{array}$ & $\begin{array}{l}w \\
\dot{w} \\
\hat{\omega}\end{array}$ & $\vec{\infty}$ & $\begin{array}{l}\tilde{N} \\
\stackrel{\sim}{\alpha}\end{array}$ & $\begin{array}{l}\infty \\
\stackrel{\infty}{ \pm}\end{array}$ & N & $\overrightarrow{\mid \vec{\omega}}$ & $\begin{array}{l}\stackrel{0}{\tilde{\infty}} \\
\dot{\infty}\end{array}$ & $\tilde{w}$ & $\approx$ & Ŭ & $\underset{0}{\overrightarrow{0}}$ & $\tilde{\omega}$ \\
\hline 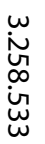 & $\dot{w}_{\mathcal{U}}^{v}$ & a & 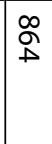 & 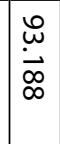 & $\begin{array}{l}\vec{\omega} \\
\underset{\omega}{\omega} \\
\underline{w}\end{array}$ & $\begin{array}{l}\vec{\omega} \\
\dot{\hat{\sigma}} \\
\text { }\end{array}$ & $\begin{array}{l}\tilde{\omega} \\
\stackrel{\omega}{\vec{\alpha}} \\
\stackrel{\sigma}{\sigma}\end{array}$ & $\begin{array}{l}\overrightarrow{\tilde{u}} \\
\dot{\vec{v}} \\
\mathbf{N}\end{array}$ & 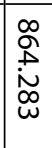 & $\begin{array}{l}\overrightarrow{\vec{U}} \\
\underline{\underline{r}}\end{array}$ & $\overrightarrow{\dot{\phi}}$ & $\begin{array}{l}\tilde{O} \\
\dot{\tilde{O}} \\
\tilde{N}\end{array}$ & $\begin{array}{l}\stackrel{\infty}{ } \\
\stackrel{\text { Dे }}{\omega}\end{array}$ & $\tilde{J}$ & \begin{tabular}{|l|} 
\\
$\dot{w}$ \\
$\dot{p}$ \\
\end{tabular} & 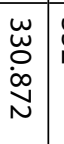 & $\underset{\sim}{\sim}$ & $\tilde{\Phi}$ \\
\hline 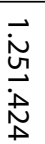 & 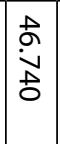 & $\ddot{w}$ & 㟧 & $\begin{array}{l}\stackrel{\omega}{\overrightarrow{0}} \\
\stackrel{\tilde{\sim}}{ \pm}\end{array}$ & \begin{tabular}{|l}
$\omega$ \\
0 \\
0
\end{tabular} & $\begin{array}{l}\vec{v} \\
\delta \\
o \\
\sim \\
\end{array}$ & $\begin{array}{l}\underset{+}{\omega} \\
\dot{\sim} \\
\infty \\
\omega\end{array}$ & 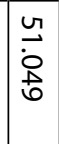 & $\begin{array}{l}\vec{\infty} \\
\stackrel{0}{0} \\
\stackrel{\omega}{\omega}\end{array}$ & $\overrightarrow{\dot{\omega}}$ & খั้ & $\begin{array}{l}w \\
\text { D } \\
\text { ज }\end{array}$ & $\begin{array}{l}\tilde{ث} \\
\stackrel{\sim}{\omega} \\
\underline{~}\end{array}$ & $\underset{\sim}{N}$ & \begin{tabular}{|l|}
$\overrightarrow{\dot{\omega}}$ \\
$\sim$ \\
$N$
\end{tabular} & 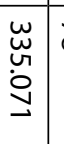 & $\grave{\infty}$ & $\tilde{v}$ \\
\hline$\tilde{\alpha}$ & $\tilde{N}$ & 0 & $\stackrel{0}{v}$ & ুু & کू & $\underset{\sim}{\sim}$ & $\overrightarrow{\overrightarrow{\vec{\sigma}}}$ & $\frac{\sigma}{a}$ & $\begin{array}{l}\mathcal{M} \\
\text { U } \\
\infty\end{array}$ & a & $\vec{w}$ & $\begin{array}{l}\overrightarrow{\dot{\iota}} \\
\alpha\end{array}$ & $\overrightarrow{\text { ज̆ }}$ & 0 & $\overrightarrow{\mathrm{u}}$ & \begin{tabular}{|l|}
$\vec{w}$ \\
$w$ \\
$w$ \\
$v$ \\
\end{tabular} & - & $\tilde{\omega}$ \\
\hline $\begin{array}{l}\vec{D} \\
\stackrel{0}{0} \\
\vec{b}\end{array}$ & $\begin{array}{l}\underset{\tilde{w}}{w} \\
v\end{array}$ & 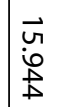 & 0 & $\overrightarrow{\stackrel{\dot{\omega}}{\omega}}$ & $\approx$ & $\begin{array}{l}\searrow \\
\searrow\end{array}$ & \begin{tabular}{|l}
$\tilde{\omega}$ \\
$\infty$ \\
$\infty$ \\
$\infty$
\end{tabular} & $\underset{\sim}{\omega}$ & 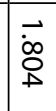 & $\underset{\overrightarrow{\vec{v}}}{\overrightarrow{\vec{\Delta}}}$ & - & $\underset{\sim}{\mathbb{N}}$ & $\begin{array}{l}\dot{v} \\
\text { D } \\
\omega\end{array}$ & 0 & 0 & $\begin{array}{l}w \\
w \\
w \\
\alpha \\
\vdots\end{array}$ & $\vec{\omega}$ & $\stackrel{\omega}{\omega}$ \\
\hline 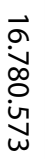 & 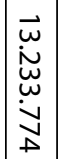 & $\bigcup_{\infty}^{\cup}$ & $\stackrel{\circlearrowleft}{0}$ & $\begin{array}{l}\stackrel{N}{\vec{N}} \\
\vec{\omega}\end{array}$ & $\underset{N}{\tilde{N}}$ & $\begin{array}{l}0 \\
\stackrel{+}{8} \\
+\end{array}$ & $\begin{array}{l}\overrightarrow{\underline{D}} \\
\stackrel{\infty}{\infty} \\
\underline{\omega}\end{array}$ & 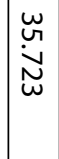 & $\begin{array}{l}\omega \\
\text { w } \\
\dot{\delta}\end{array}$ & $\begin{array}{l}\stackrel{\sim}{\mathbf{w}} \\
\mathrm{w}\end{array}$ & ڤ్ & $\begin{array}{l}\tilde{U} \\
\stackrel{N}{\dot{O}} \\
\tilde{\sigma}\end{array}$ & $\begin{array}{l}\overrightarrow{\vec{\sigma}} \\
\underset{\sim}{\sim} \\
\sim\end{array}$ & 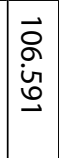 & $\begin{array}{l}\overrightarrow{\dot{v}} \\
\mathrm{v}\end{array}$ & \begin{tabular}{|l|} 
\\
$\vec{u}$ \\
$u$ \\
$u$ \\
$\dot{\omega}$ \\
$o$
\end{tabular} & $\mathfrak{w}_{\mathfrak{w}}^{w}$ & $\underset{w}{w}$ \\
\hline 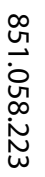 & 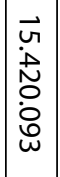 & $\begin{array}{l}\vec{v} \\
N\end{array}$ & $\begin{array}{l}\text { ò } \\
\dot{8}\end{array}$ & 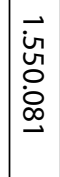 & 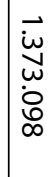 & $\begin{array}{l}\vec{a} \\
\stackrel{u}{\tilde{\Sigma}} \\
\Omega\end{array}$ & 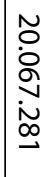 & 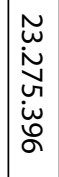 & $\begin{array}{l}\vec{\omega} \\
\stackrel{p}{0} \\
\dot{o} \\
\stackrel{+}{\dot{0}} \\
\text { v }\end{array}$ & 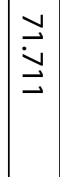 & $\begin{array}{l}\tilde{\vec{a}} \\
\overrightarrow{\hat{\alpha}} \\
\vec{\partial}\end{array}$ & $\begin{array}{l}\overrightarrow{\vec{H}} \\
\dot{\dot{0}} \\
\text { ज } \\
\dot{\mathscr{O}}\end{array}$ & 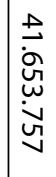 & 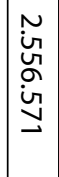 & 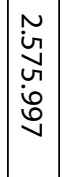 & 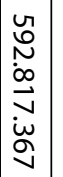 & $\begin{array}{l}\vec{\omega} \\
\dot{\omega} \\
\dot{w} \\
\omega\end{array}$ & 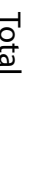 \\
\hline
\end{tabular}

FONTE: Dados básicos: MapBiomas (2019b). Elaborado pelos autores. 
Resultado dos conqlomerados cross-section 1985/2018.

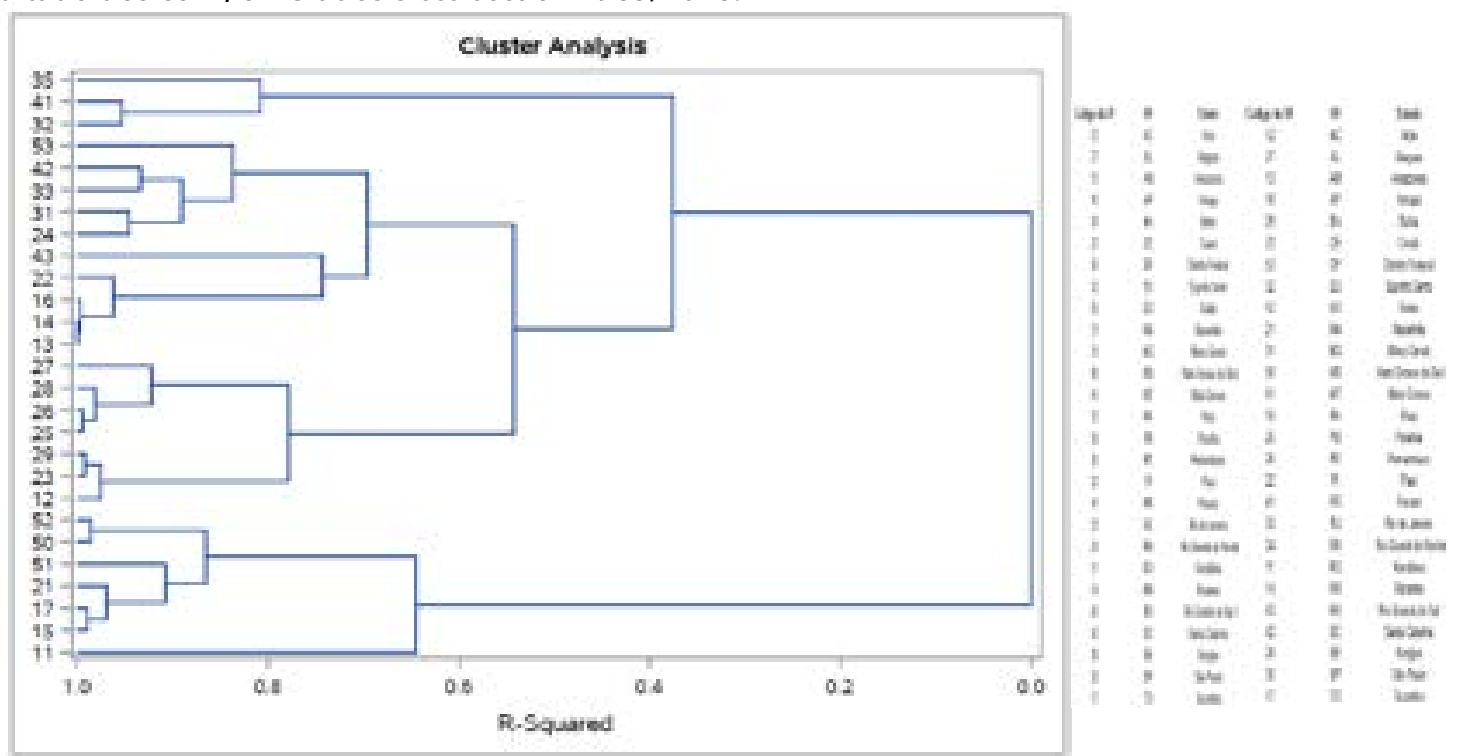

Resultado dos conqlomerados de séries temporais 1985-2018 - transição de floresta natural para pastagem.

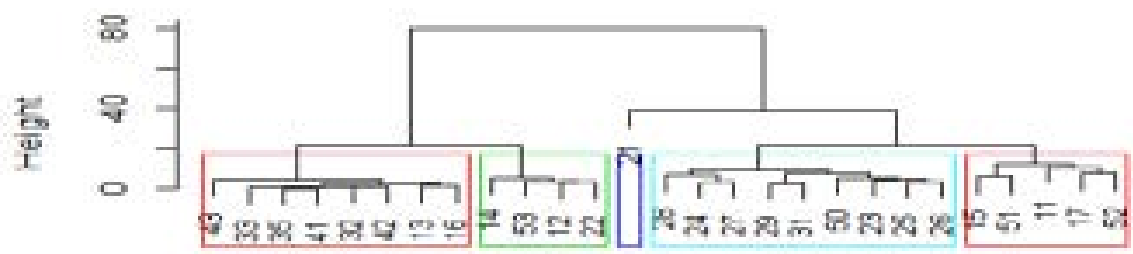

stats: helust (", "complete")

Resultado dos conqlomerados de séries temporais 1985-2018 - 15 transições mais relevantes.

\section{Cluster Dendrogram}

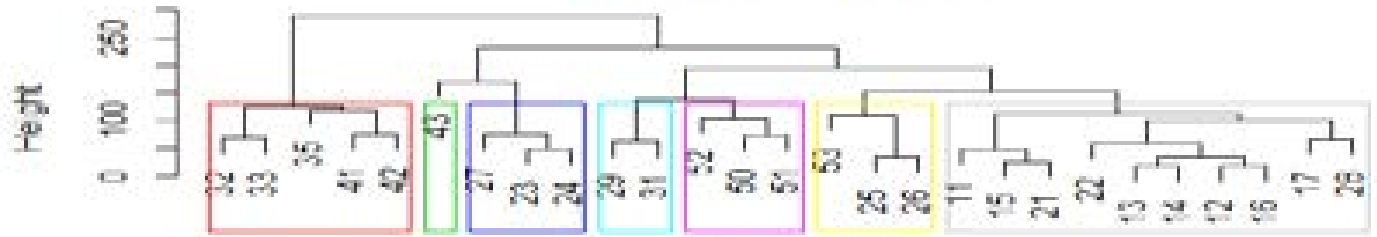

stats:aas.dist(distrmat)

stats helust (", "complete") 